\title{
Forecasting Analysis of Carbon Emission from China's Coal-fired Power Enterprises Based on the Logistic Model
}

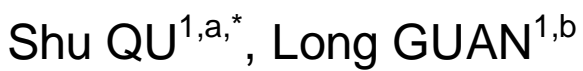 \\ ${ }^{1}$ Harbin Institute of Technology, Harbin 150001, China \\ aqushu2013@163.com, bguanlong@hit.edu.cn \\ ${ }^{*}$ Corresponding author
}

Keywords: Logistic model, carbon emission, low-carbon economy.

\begin{abstract}
As the biggest carbon emission country in the world, China has to pay more attention on environmental issues. Coal-fired power enterprises are the major sources of carbon emissions in China. How to predict and analyze the carbon emissions of China's coal-fired power enterprises is a critical issue in the field of low-carbon economy research. This paper calculates 1996-2011 China's coal-fired power enterprises carbon emissions according to the inventory method, analyze the existing situation carbon emissions, and predicts the further trend of China's coal-fired power enterprises carbon emissions through Logistic model. The result shows that the carbon emissions will continue to increase in the further, so it is necessary to encourage energy efficiency and reduce energy consumption per unit to achieve low-carbon economy development.
\end{abstract}

\section{Introduction}

Nowadays China's carbon emissions is persistently and rapidly growing and China has become the biggest greenhouse gas emission country in the world. Based on relative data, $\mathrm{CO}_{2}$ coming from energy consumption accounts for $80 \%$ of China's total greenhouse gas emissions. Because China's current energy situation is "rich in coal, short in oil and gas", China's energy consumption is mainly based on coal and 50\% of the coal is used for thermal power generation. Therefore, it is necessary and meaningful to analyze and predict the carbon emissions from China's coal-fired power enterprises as the following two aspects, (1) Helping coal-fired power enterprises to be aware of environmental changes and to make low-carbon development strategies. (2) Helping our country to achieve optimal allocation of resources. The national energy sector will form macroeconomics policies and reconfigure social resources based on this result.

\section{The Calculation of Carbon Emissions of China's Coal-fired Power Enterprises Inventory Calculating Method}

Inventory method is to draw up a greenhouse gas inventory in accordance with the requirements of IPCC. Energy consumption is the major event causing carbon emissions. So carbon emissions can be determined based on the amount of fuel consumption and different fuels' emission factors. Formula can be written as follows,

Carbon emissions of energy consumption $=($ fuel consumption (heat unit $) \times$ carbon amount of unit fuel) $\times$ carbon oxidation rate of fuel combustion process

\section{Data Select}

Since there is no official statistics of the carbon emissions specific in the coal-fired power 
enterprises, the carbon emissions will be estimated based on existing fossil energy consumption statistics. Although China's coal-fired power enterprises use various type of fuel, the main fuels are only coal, crude oil, gasoline, diesel oil, fuel oil and natural gas.

Table 1 1996-2011 China's coal-fired corporations' main energy consumption [10 ${ }^{4} \mathrm{t}$ coal standard] Source, China Energy Statistical Yearbook (1997-2012)

\begin{tabular}{ccccccc}
\hline & Coal & Crude oil & Diesel oil & Fuel oil & Natural oil & Total \\
\hline 1996 & 24717.02 & 56.99 & 218.17 & 781.50 & 42.22 & 25815.9 \\
1997 & 25982.15 & 53.77 & 636.76 & 740.38 & 115.73 & 27528.79 \\
1998 & 26259.17 & 62.20 & 172.22 & 876.82 & 87.29 & 27457.7 \\
1999 & 28079.33 & 67.04 & 185.65 & 799.66 & 75.53 & 29207.21 \\
2000 & 30288.72 & 71.09 & 196.15 & 718.38 & 90.60 & 31364.94 \\
2001 & 31873.97 & 68.24 & 207.12 & 739.84 & 77.44 & 32966.61 \\
2002 & 35228.19 & 65.51 & 194.71 & 805.24 & 65.82 & 36359.47 \\
2003 & 40627.80 & 78.60 & 233.73 & 932.34 & 78.87 & 41951.34 \\
2004 & 44603.54 & 15.09 & 288.56 & 1260.97 & 113.36 & 46281.52 \\
2005 & 51157.37 & 17.80 & 315.97 & 975.88 & 187.76 & 52654.78 \\
2006 & 59436.26 & 19.16 & 269.43 & 818.82 & 223.74 & 60767.41 \\
2007 & 67215.50 & 13.31 & 199.38 & 499.02 & 480.61 & 68407.82 \\
2008 & 67061.11 & 7.42 & 159.50 & 306.62 & 488.30 & 68022.95 \\
2009 & 69861.49 & 3.66 & 130.79 & 170.30 & 799.67 & 70965.91 \\
2010 & 74796.88 & 3.10 & 98.09 & 109.30 & 131.98 & 75139.35 \\
2011 & 85235.89 & 9.45 & 33.79 & 53.68 & 154.85 & 85487.66 \\
\hline
\end{tabular}

\section{Carbon Emission Factor}

Based on the IPCC (United Nations Intergovernmental Panel on Climate change) National Greenhouse Gas Emission Inventory Guidebook, carbon dioxide emissions is calculated as,

$$
\text { Carbon emissions }=\Sigma \text { energy consumption of energy } \mathrm{E} * \text { emission factors of energy } \mathrm{E}
$$

E is a kind of energy. According to the selected China's coal-fired enterprises main fuel fuels carbon emission factors are given in Table 2-3 below.

Table 2 Carbon emission factor of several energy $\left[10^{4} \mathrm{t} / 10^{4} \mathrm{t}\right]$

Source, China Statistical Yearbook

\begin{tabular}{cccccc}
\hline Type of energy & Raw coal & Crude oil & Diesel oil & Energy oil & Natural gas \\
\hline Carbon emission factors & 0.7559 & 0.5857 & 0.5921 & 0.6185 & 0.4483 \\
\hline
\end{tabular}

\section{The Calculation of 1996-2011 China's Coal-fired Power Corporations' Carbon Emissions}

Using IPCC carbon emissions calculation formula and carbon emission factors, and the amount of 1996-2011 China's coal-fired power enterprises primary energy consumption provided by the China Statistical Yearbook, this paper calculates 1996-2011 China's coal-fired power enterprises carbon emissions in Table 3 below. 
Table 3 1996-2011 China's coal-fired power enterprises carbon emissions [ $\left[10^{4} \mathrm{t}\right]$

\begin{tabular}{llllllll}
\hline $\mathbf{1 9 9 6}$ & $\mathbf{1 9 9 7}$ & $\mathbf{1 9 9 8}$ & $\mathbf{1 9 9 9}$ & $\mathbf{2 0 0 0}$ & $\mathbf{2 0 0 1}$ & $\mathbf{2 0 0 2}$ & $\mathbf{2 0 0 3}$ \\
\hline 19142.38 & 20341.35 & 20350.23 & 21668.83 & 23285.71 & 24483.01 & 27016.88 & 31168.71 \\
\hline $\mathbf{2 0 0 4}$ & $\mathbf{2 0 0 5}$ & $\mathbf{2 0 0 6}$ & $\mathbf{2 0 0 7}$ & $\mathbf{2 0 0 8}$ & $\mathbf{2 0 0 9}$ & $\mathbf{2 0 1 0}$ & $\mathbf{2 0 1 1}$ \\
\hline 34354.62 & 39129.31 & 45211.00 & 50899.46 & 50641.62 & 52771.29 & 56104.59 & 63850.38 \\
\hline
\end{tabular}

The line chart is given below,

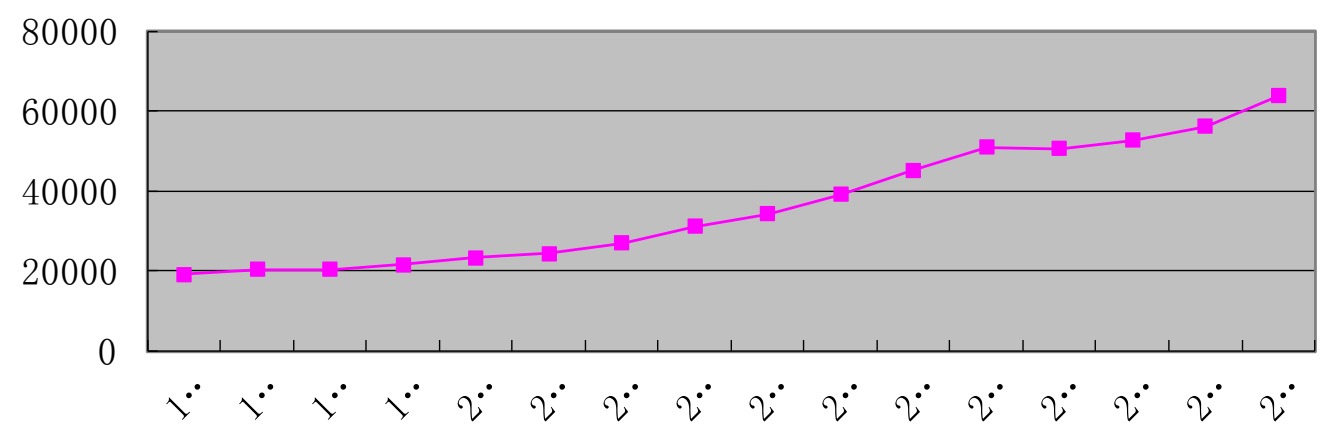

Fig. 1 1996-2011 China's coal-fired power enterprises carbon emissions $\left[10^{4} \mathrm{t}\right]$

\section{The Analysis of the Existing Situation of China's Coal-fired Power Enterprises Carbon Emissions}

From 1996 to 1999, the increase velocity of carbon emissions is comparative slow; from 1999 to 2001, there was an obvious increase in the growth of the carbon emissions, and the average annual growth rate reached $6.29 \%$, carbon emissions increased by 28,141,800 tons; from 2002 to 2007, the growth rate of carbon emissions entered a rapid increasing phase. The average annual growth rate was $13.51 \%$, and from 2008 to 2011 , the growth rate of carbon emissions slowed down and the average annual growth rate was $8.03 \%$.

From the data presented above, a general growth rise of coal-fired power enterprises can be seen. Companied with China's industrial economic development, especially heavy industry, the growth rate of energy consumption increased. In order to satisfy the industrial need of electricity, coal-fired power enterprises increase their generation unit construction and power generation. As a result, the consumption of fossil fuel and carbon emissions increased.

\section{The Prediction of Carbon Emissions of China's Coal-fired Power Enterprises}

\section{Logistic Model Statistical Test and Estimation Method}

Logistic model, also known as block growth model, does not require stringent assumptions, overcomes the limitations of linear equations constrained by statistical assumptions, and have inherent growth rate and capacity parameters, so it can well describe the energy consumption and feedback mechanism of economic growth and environmental impacts.

Logistic model is expressed,

$$
\begin{aligned}
& \frac{d x}{d t}=r x\left[1-\frac{x}{K}\right] \\
& x_{0}=\left.x\right|_{\mathrm{t}=0}
\end{aligned}
$$


The formula (1) can be solved as follow,

$$
\left\{\begin{array}{l}
x=K /\left[1+e^{-r t}\left(\frac{K}{x_{0}}-1\right)\right] \\
x_{0}=\left.x\right|_{t=0}
\end{array}\right.
$$

$\mathrm{x}$ is dependent variable, which means China's coal-fired power enterprises carbon emissions; $\mathrm{r}$ is carbon emission factor; $\mathrm{t}$ is independent variable, which means time; $\mathrm{K}$ is a constant, which means the limits of carbon emissions.

\section{The Algorithm Optimization Based on the Least Squares Method}

To estimate the equation, set

$$
\left\{\begin{array}{l}
Y=\ln \frac{K-x}{x} \\
\frac{K}{x_{0}}-1=e^{a}
\end{array}\right.
$$

Deform Formula (1) and obtain the linear equation

$$
Y=a-r t
$$

To estimate parameter $\mathrm{r}$ and $\mathrm{a}$, transform the sample data $\left\{\mathrm{X}_{\mathrm{t}}, \mathrm{t}=1,2, \ldots, \mathrm{n}\right\}$ to $\left\{Y_{\mathrm{t}}\right\}$ in a special value of $\mathrm{K},\left\{Y_{\mathrm{t}}\right\}$ is carried out through least square fitting method, use point parameter estimation to obtain the value of a and $\mathrm{r}$, and evaluate the predicted values of energy consumption $\left\{\hat{Y}_{\mathrm{t}}\right\}$. In the estimation of equation (8), economic qualitative analysis should be combined with statistical quantitative tests. Reasonable parameter estimation method is, determining the energy consumption of $\mathrm{K}$ based on the sample data and coefficient of determination $\mathrm{R}^{2}$ and obtaining the corresponding parameters.

$$
\begin{gathered}
R^{2}=1-\frac{\sum e_{t}^{2}}{\sum(Y-\hat{Y})^{2}}, \\
e_{t}=Y-\hat{Y}, \hat{Y}=\frac{\sum Y_{t}}{n} .
\end{gathered}
$$

\section{To Optimize Limit Value of China Coal-fired Power Enterprises Carbon Emissions}

In the progress of optimizing the simulation, the critical first step is to determine an effective value range of the initial $\mathrm{K}\left[\mathrm{K}_{\min }, \mathrm{K}_{\max }\right] . \mathrm{K}_{\min }$ is at least not less than the historical energy consumption sample data $\left\{\mathrm{X}_{\mathrm{t}}, \mathrm{t}=1,2, \ldots, \mathrm{n}\right\} . \mathrm{K}_{\max }$ can be set according to specific practical engineering experience and computer data processing capabilities, and is generally between $2 \mathrm{~K}_{\max } \sim 10 \mathrm{~K}_{\max }$.

In the Climate Change Conference in Copenhagen and executive meeting of the State Council, December 2009, China decided to decline the carbon dioxide emissions per unit of GDP by 40\%-45\% compared to 2005 in 2020. 
In Table 3, the approximate value range of $K$ in the next 10 years is [70000, 120000] $\left(10^{4} \mathrm{t}\right.$ coal standard). According to the model mentioned above, the result of regression analysis is presented in Table 4.

Table 4 Result of the Logistic model regression analysis

\begin{tabular}{ccccccc}
\hline $\mathrm{K}$ & 70000 & 80000 & 90000 & 100000 & 110000 & 120000 \\
\hline $\mathrm{R}^{2}$ & 0.925686 & 0.955572 & 0.964009 & 0.967905 & 0.970111 & 0.971513 \\
\hline $\mathrm{a}$ & 1.593271 & 1.619864 & 1.702451 & 1.793148 & 1.882104 & 1.966649 \\
\hline $\mathrm{r}$ & -0.2024 & -0.16703 & -0.14947 & -0.1385 & -0.1309 & -0.12529 \\
\hline
\end{tabular}

According to Table 5, when $K=120000$, the coefficient of determination $R^{2}=0.971513, R^{2}$ fits the goodness. At this time, $x_{t}=120000 /\left(1+e^{1.966649+0.12529 t}\right)$.

\section{Error Analysis of the Data}

The error analysis between the actual value and estimated value of 1996-2010 China's coal-fired power enterprises carbon emissions is presented in Table 5. In Table 6, it can be found that the error between the two values is very small. This shows that the results of the Logistic model established by this paper has high goodness of fit the historical data.

Table 5 The error analysis between the actual value and estimated value of 1996-2010 China's coal-fired power corporation carbon emissions $\left[10^{4} \mathrm{t}\right.$ coal standard]

\begin{tabular}{cccc}
\hline year & Predictive value & Actual value & Error \\
\hline 1996 & 16426.86 & 19142.38 & 0.142 \\
1997 & 18285.34 & 20341.35 & 0.101 \\
1998 & 20312.85 & 20350.23 & 0.002 \\
1999 & 22515.41 & 21668.83 & -0.039 \\
2000 & 24897.15 & 23285.71 & -0.069 \\
2001 & 27459.87 & 24483.01 & -0.122 \\
2002 & 30202.6 & 27016.88 & -0.118 \\
2003 & 33121.23 & 31168.71 & -0.063 \\
2004 & 36208.18 & 34354.62 & -0.054 \\
2005 & 39452.19 & 39129.31 & -0.008 \\
2006 & 42838.24 & 45211 & 0.052 \\
2007 & 46347.69 & 50899.46 & 0.089 \\
2008 & 49958.5 & 50641.62 & 0.013 \\
2009 & 53645.72 & 52771.29 & -0.012 \\
2010 & 57382.13 & 56104.59 & -0.022 \\
2011 & 61139 & 63850.38 & 0.042 \\
\hline
\end{tabular}




\section{The Prediction Analysis of China's Coal-fired Power Enterprises Carbon Emissions}

Table 6 The prediction of 2012-2020 China's coal-fired power enterprises carbon emissions based on the Logistic models $\left[10^{4} \mathrm{t}\right.$ coal standard]

\begin{tabular}{ccccccccc}
\hline $\mathbf{2 0 1 2}$ & $\mathbf{2 0 1 3}$ & $\mathbf{2 0 1 4}$ & $\mathbf{2 0 1 5}$ & $\mathbf{2 0 1 6}$ & $\mathbf{2 0 1 7}$ & $\mathbf{2 0 1 8}$ & $\mathbf{2 0 1 9}$ & $\mathbf{2 0 2 0}$ \\
\hline 64886.9 & 68596.8 & 72240.9 & 75793.0 & 79230.1 & 82532.1 & 85682.4 & 88668.5 & 91481. \\
5 & 9 & 2 & 9 & 7 & 2 & 8 & 1 & 2 \\
\hline
\end{tabular}

The line chart is given below,

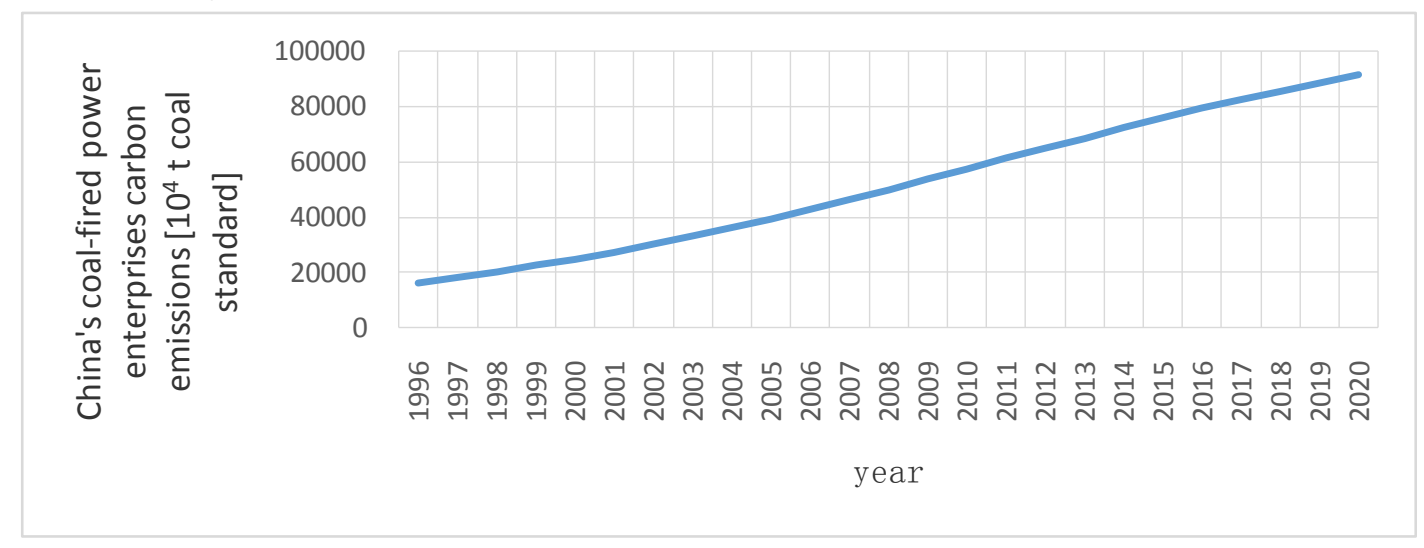

Fig. 2 Estimated value of 1996-2020 China's coal-fired power enterprises carbon emissions based on Logistic model

According to the result of the prediction of 2012-2020 China's coal-fired power enterprises carbon emissions based on Logistic model, it can be found that, if in the law of development remains unchanged, the growth trend of carbon emissions was sustained and the annual average growth rate reached $4.39 \%$. In order to meet the economic growth rate rapidly growing and resolve the increasingly severe power shortage, China's coal-fired power enterprises must increase the installed capacity and power generation capacity, which lead the carbon emissions grow more than three times in a short period of ten years.

\section{Summary}

This paper calculates 1996-2011 China's coal-fired power enterprises carbon emissions through the inventory method and predicts the further trend of China's coal-fired power enterprises carbon emissions through Logistic model. There come the following conclusions,

(1) According to the calculation of the carbon emissions of China's coal-fired power enterprise, it can be found that the coal-fired power enterprises carbon emissions growth rate agreed with energy consumption structure, electricity consumption growth rate and economic growth rate. Therefore, adjusting energy structure and improving the proportion of clean energy generation are the most effective ways to reduce carbon emissions from coal-fired power enterprises.

(2) In the further, the carbon emissions of China's coal-fired power enterprises will continue to increase. Although China has made the promise in the World Climate Conference in Copenhagen, affected by the rapid development of extensive economy, technology limits and other factors, the carbon emission of China's coal-fired enterprises will not decrease in further. Improving energy efficiency by technological progress and reducing fired power unit energy consumption levels are what a coal-fired power enterprise should do to achieve low-carbon economic and sustainable 
development.

\section{References}

[1] MI Guofang, ZHAO Tao, Evaluation and Prediction of Carbon Emissions from Thermal Power Enterprises in China, Resources Science, Vol.34, No.10, Oct 2012, 34(10),1835-1831

[2] ZHAO Liurong, TIAN Lixin, Logistic Model for Energy Resource Structure in Chinese Western Regional and Its Forecast, Chinese Journal of Management, Vol.5, No.5, Sep.2008,678-681

[3] YANG Bo, TAN Zhanglu, Analysis on China National Energy Consumption Based on the Logistic Model, Science and Technology Management Research, No.12, 2013, 45-48

[4] QI Shaozhou, FU Kun, Comparative Analysis of the Accounting Method of Province Carbon Emission during the Low Caron Transition, Wuhan University Journal, Vol.66, No.2, Mar 2013, $85-92$

[5] China Statistical Yearbook (1997-2012) 